\title{
IS/IT STRATEGIC PLANNING PADA PERUSAHAAN MONO JAYA CILACAP JAWA TENGAH
}

\author{
Anjar Sylvia Rahmawati ${ }^{1}$, Akto Hariawan ${ }^{2}$, Ito Setiawan ${ }^{3}$, Fiby Nur Afiana ${ }^{4}$, \\ ${ }^{1,3,4}$ Prodi Sistem Informasi, Universitas AMIKOM Purwokerto \\ Jl. Letjen Pol Sumarto Watumas Purwanegara Purwokerto \\ ${ }^{2}$ Prodi Teknik Informatika, Universitas AMIKOM Purwokerto \\ Jl. Letjen Pol Sumarto Watumas Purwanegara Purwokerto \\ E-mail : ${ }^{1}$ anjarsylvia08@gmail.com, ${ }^{2}$ akto.85@gmail.com, \\ 3itosetiawan@amikompurwokerto.ac.id, ${ }^{4}$ fiby@amikompurwokerto.ac.id
}

\begin{abstract}
At present business competition in Indonesia is getting tougher, including business competition in the field of wig making. PT Mono Jaya is one of the companies engaged in the production of wigs that are in Kroya, Cilacap district, Central Java. To increase competitiveness against its competitors, companies must be able to create new innovations and use information systems that are in accordance with the needs of the company as a support to improve performance, increase competitiveness against its competitors, and realize the company's goals. But to get an information system that fits the needs of the company, it requires an information system strategic planning. This study uses the Ward And Peppard method, the tools used are SWOT analysis, Value Chain analysis, McFarlan Strategic Grid analysis, Five Force Porter Model analysis, Critical Success Factor (CSF) analysis, and Balaced ScoreCard (BSC) analysis. The final results of this study are in the form of information system portfolio recommendations that are needed by PT Mono Jaya to improve the competitiveness of the company.
\end{abstract}

Keywords: IS/IT, Strategic Planning, Ward and Peppard

\section{PENDAHULUAN}

Cilacap merupakan salah satu kabupaten yang berada di Provinsi Jawa Tengah dengan luas wilayahnya sekitar $6,2 \%$ dari jumlah total wilayah Jawa tengah. Kabupaten Cilacap terdiri atas 24 kecamatan. Salah satu Kecamatan tersebut adalah Kecamatan Kroya(Kantor Kependudukan dan Catatan Sipil Kab. Cilacap, 2008).
Banyak perusahaan yang berada di Kecamatan Kroya salah satunya adalah Perusahaan rambut palsu (wig) Mona Jaya.

Mono Jaya merupakan salah satu perusahaan yang bergerak dalam bidang produksi rambut palsu yang berada kabupaten Cilacap Jawa Tengah. PT Mono Jaya berdiri pada bulan Desember tahun 2012. PT Mono Jaya merupakan 
salah satu pabrik pertama di Kroya yang memproduksi rambut palsu atau wig. Perusahaan ini memiliki pangsa pasar sampai luar negeri namun selama ini proses pemasukan data-data untuk laporan proses bisnis kurang maksimal karena masih menggunakan laporan pembukuan tertulis. Masih sering ditemukan kesulitan dalam mengolah data-data proses bisnis terutama pada masalah manajemen keuangan.

Selain itu masih kurang efektifnya proses pada melakukan pengecekan terhadap data pelanggan, data barang, data uang masuk dan keluar, yang memakan waktu lama karena harus membuka buku dan harus mencari data informasi didalam banyaknya buku dan data-data lainnya. Perusahaan Mona jaya memiliki Visi menjadi produsen produk rambut palsu (wig) terkemuka di Indonesia. Selain visi, PT Mono Jaya juga memiliki misi yaitu menghasilkan produk rambut palsu (wig) yang aman, nyaman, dan menghasilkan produk yang berkualitas sesuai dengan prosedur yang berlaku.

Dalam mencapai visi dan misi dan juga menghadapi persaingan dengan perusahaaan yang lain maka perlu adanya terbobosan dalam proses tata kelola manajemen sampai dengan proses penjualan produk. Terobosan saat ini adalah penggunaan teknologi informasi dalam menjalankan proses bisnis perusahaan, dari proses manajemen sampai dengan proses transaksi perusahaan(Anharudin, 2015). Pada saat ini Perusahaan Mono Jaya belum mempunyai sistem informasi yang terkomputerisasi untuk menangani proses bisnisnya. Perusahaan Mona Jaya belum mempunyai rencana SI/TI (Sistem Informasi dan Teknologi Informasi) untuk menghadapi ancaman proses bi snis dimasa yang akan datang.

Sistem informasi sangat berkembang dengan cepat (Anharudin, 2015), banyak pimpinan perusahaan memberikan penilaian terhadap sistem informasi sebagai sumber daya penting dalam keberhasilan strategi bisnis mereka (Hoque, Hossin, \& Khan, 2016) (Khani, Nor, Bahrami, \& Hakimpoor, 2012). Banyak perusahaan berinvestasi di bidang teknologi informasi namun banyak juga juga yang tidak berhasil karena mengimplementasian sistem informasi yang kurang tepat (Mawlan, n.d.). Penggunaan teknologi informasi hanya akan berhasil jika sistem informasi diterapkan selaras dengan strategi pengembangan sistem bisnis perusahaan (Brumec \& $\left.\mathrm{Vr}^{\longleftarrow}, 2002\right)$. 
Perencanaan strategis SI/TI merupakan suatu proses untuk mengidentifikasi gambaran aplikasi SI (Sistem Informasi) berbasis teknologi yang akan mendukung perusahaan dalam pelaksanaan rencana bisnis dan merealisasikan tujuan bisnisnya (Ward \& Peppard, n.d.). Dengan perusahaan melakukan Perencanaan strategis SI/TI maka dapat membantu perusahaan dalam mengatasi permasalahan yang ada (Wijaya \& Widiawan, 2017) (Saravi, 2016).

Salah satu kerangka yang digunakan untuk melakukan perancangan strategis adalah kerangka milik ward and peppard (Fahana, 2018). Serta didukung dengan beberapa metode analisis yang seperti analisis SWOT, analisis PEST, analisis CSF, analisis Five Force's Model dan analisis Mc Farlan Strategic Grid (Septiana, 2017).

\section{METODE}

\section{Metode Pengumpulan Data}

a. Studi Kepustakaan

Studi kepustakaan berhubungan dengan kajian teoritis dan referensi dengan mempelajari buku, jurnal, prosiding yang ada hubungannya dengan obyek penelitian atau sumbersumber lain yang mendukung penelitian (Sugiyanto, 2012) (Sunyoto, 2016). Peneliti pencari studi pustaka di perpustakaan dan internet terkait dengan tema penelitian strategic planning sistem informasi.

b. Studi Lapangan

Studi lapangan adalah suatu cara melakukan pengamatan langsung terhadap aktifitas tempat penelitian(Sunyoto, 2013). Studi ini digunakan beberapa metode yaitu:

1) Wawancara

Melakukan komunikasi terhadap orang tertentu dengan maksud tertentu(Arikunto, 2010). Wawancara dilakukan terhadap pimpinan dan para karyawan.

2) Dokumentasi

Dokumen merupakan catatan kegiatan yang sudah terjadi dalam kegiatan tertentu. Dokumen biasanya berbentuk tulisan, gambar dan berbentuk karya(Sudaryono, 2015). Dokumentasi yang diperoleh seperti Peraturan-peraturan, foto kegiatan dan lainya yang mendukung penelitian.

3) Kuisioner

Kuisioner adalah cara untuk mendapatkan data melalui pertanyaan atau pernyataan 
kepada orang yang dijadikan responden untuk dijawabnya (Sekaran, 2010). Kuisioner diberikan kepada para karyawan perusahaan.

\section{Konsep Penelitian}

Dalam proses penelitian dibutuhkan konsep penelitian atau kerangka penelitian guna membantu proses berjalannya penelitian. Dengan adanya kerangka penelitian ini penelitian dapat lebih terstruktur saat penelitian berjalan. Konsep penelitian dapat dilihat pada gambar 1. kosep penelitian :

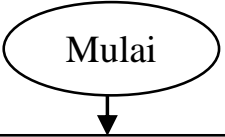

Pengumpulan Data

(Studi Pustaka dan Studi Lapangan)

Tahap Analisis Perancangan Strategis Meliputi :

1. Analisis Internal Bisnis

2. Analisis Internal IS/IT

3. Analisis Eksternal Bisnis

4. Analisis Eksternal IS/IT

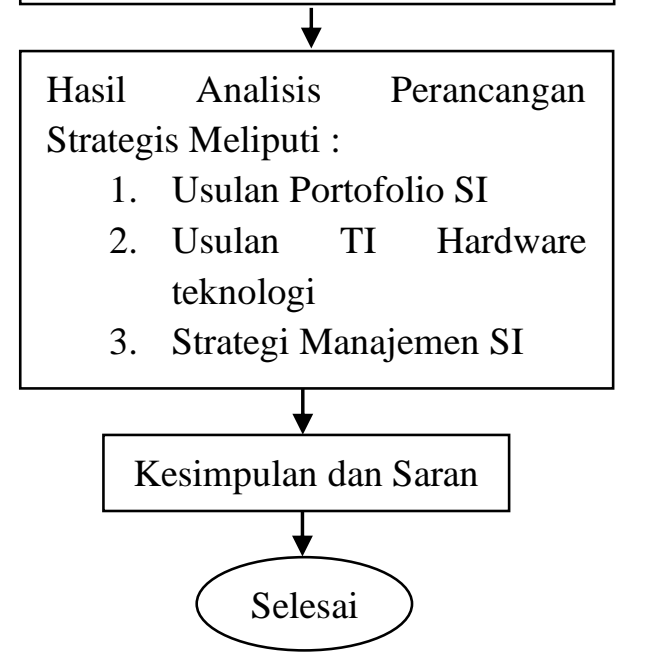

Gambar 1. Konsep penelitian
Konsep Penelitian yang terdiri dari tahapan-tahapan di atas dapat dijelaskan seperti berikut ini :

a. Pengumpulan data

Dalam tahap ini adalah mengumpulkan data yang dibutuhkan dalam penelitian, datadata tersebut diperoleh dari PT Mono Jaya. Pengumpulan data dilakukan dengan metode dokumentasi yang akan menjadi acuan dalam penelitian, selain itu pengumpulan data dilakukan dengan menggunakan metode wawancara dengan personal yang terkait dan studi pustaka seperti buku dan jurnal.

b. Tahap Analisis Lingkungan Bisnis

Pada tahap ini menganalisis lingkungan bisnis PT Mono Jaya dan menganalisis kondisi bisnis PT Mono Jaya saat ini. Untuk membuat suatu perencanaan strategis sistem informasi maka perlu mengetahui kondisi bisnis perusahaan saat ini seperti Visi, Misi, struktur organisasi, sistem informasi yang digunakan saat ini, kelebihan dan kekurangan perusahaan secara umum. Adapun tahapan analisisnya adalah sebagai berikut : 
1) Tahap analisis lingkungan bisnis menggunakan tool critical success factors

Menganalisis lingkungan bisnis PT Mono Jaya dengan cara mengidentifikasi faktor-faktor yang menentukan keberhasilan PT Mono Jaya dalam mencapai tujuan perusahaan.

2) Tahap analisis lingkungan bisnis menggunakan tool value chain Menganalisis lingkungan bisnis PT Mono Jaya dengan cara mengidentifikasi proses bisnis atau aktivitas yang ada di PT Mono Jaya, dimana aktivitas ini ada aktivitas bisnis utama dan aktivitas bisnis pendukung.

3) Tahap analisis lingkungan bisnis menggunakan tool SWOT

Mengidentifikasi kekuatan, kelemahan, peluang dan ancaman yang ada di PT Mono Jaya. Setelah itu maka selanjutnya membuat strategi agar peluang bisa didapatkan dengan memanfaatkan kekuatan perusahaan, sedangkan kekurangan serta ancaman dapat diatasi dengan memanfaatkan kekuatan.p analisis lingkungan bisnis menggunakan tool five force model porter

Pada tahap ini mengidentifikasi ancaman dari perusahaan baru, pesaing-pesaing yang sudah ada, kekuatan menawar pemasok dan ancaman produk.

4) Tahap analisis lingkungan bisnis menggunakan tool balaced scorecard

Mengidentifikasi finansial, pelanggan, proses bisnis dan pembelajaran dan perkembangan yang ada di PT Mono Jaya .

5) Tahap analisis McFarlan Strategic Grid (Pemetaan strategi bisnis dengan kebutuhan informasi)

Setelah menganalisis dengan kelima tools tersebut, maka selanjutnya adalah membuat pemetaan strategis yang didapat dari hasil analisis kelima tools Ward and Peppard.

c. Hasil Analisis Perancangan Strategi Portofolio yang dihasilkan pada tahap ini adalah portofolio yang dibutuhkan guna meningkatkan proses bisnis perusahaan dan meningkatkan daya saing perusahaan, yang dapat menunjang kebutuhan sistem informasi sebagai bahan acuan untuk merencanakan 
kebutuhan perusahaan dalam pemanfaatan hardware, software serta strategi sistem informasi dimasa yang akan datang. Perancangan portofolio sistem informasi menggunakan McFarlan Strategic Grid dan Critical Success Factors.

d. Kesimpulan dan Saran

Pada tahap ini akan ditarik kesimpulan dari tahapan yang sudah dilakukan, dan juga memberikan saran terhadap perusahaan.

\section{HASIL DAN PEMBAHASAN}

\section{Analisis Internal Bisnis}

Analisis SWOT (Strengths, Weaknesses, Opportunities, Threats) dilakukan di PT Mono Jaya dengan mengidentifikasi kekuatan dan faktor-faktor positif yang berasal dari lingkungan internal organisasi, kelemahan dan faktor-faktor negatif dari lingkungan internal organisasi, peluang atau kesempatan yang mungkin akan muncul dan keuntungan dari faktor eksternal, dan ancaman atau resiko yang dipengaruhi oleh faktor eksternal organisasi. Berikut analisis SWOT PT Mono Jaya :

Strengths (kekuatan) dan Weaknesses (kelemahan)

Adapun kekuatan dan kelemahan PT Mono Jaya adalah sebagai berikut :
Tabel 1. Kekuatan dan kelemahan

\begin{tabular}{|l|l|}
\hline Strengths (kekuatan) & \multicolumn{1}{|c|}{$\begin{array}{c}\text { Weaknesses } \\
\text { (kelemahan) }\end{array}$} \\
\hline $\begin{array}{l}\text { Citra perusahaan } \\
\text { yang baik dimata } \\
\text { pelanggan. }\end{array}$ & $\begin{array}{l}\text { Pembuatan laporan } \\
\text { masih secara } \\
\text { manual. }\end{array}$ \\
\hline $\begin{array}{l}\text { Letak perusahaan } \\
\text { yang strategis di } \\
\text { daerah Kroya. }\end{array}$ & $\begin{array}{l}\text { Kurang efektif } \\
\text { dalam } \\
\text { penggunaan waktu. }\end{array}$ \\
\hline $\begin{array}{l}\text { Mempunyai surat ijin } \\
\text { usaha }\end{array}$ & $\begin{array}{l}\text { Lambatnya proses } \\
\text { pencatatan data }\end{array}$ \\
\hline $\begin{array}{l}\text { Mempunyai produk } \\
\text { rambut palsu yang } \\
\text { berkualitas. }\end{array}$ & $\begin{array}{l}\text { Kurangnya media } \\
\text { promosi untuk } \\
\text { menawarkan produk } \\
\text { rambut palsu }\end{array}$ \\
\hline
\end{tabular}

Opportunities (Peluang) dan Threats (Ancaman).

Adapun peluang dan ancaman PT Mono Jaya adalah sebagai berikut :

Tabel 2. Peluang dan ancaman

\begin{tabular}{|l|l|}
\hline \multicolumn{1}{|c|}{$\begin{array}{c}\text { Opportunities } \\
\text { (Peluang) }\end{array}$} & \multicolumn{1}{c|}{$\begin{array}{c}\text { Threats } \\
\text { (Ancaman) }\end{array}$} \\
\hline $\begin{array}{l}\text { Semakin ban } \\
\text { yaknya pengguna } \\
\text { rambut palsu } \\
\text { sebagai fashion. }\end{array}$ & $\begin{array}{l}\text { Tingginya persaingan } \\
\text { di industri pembuatan } \\
\text { rambut palsu (wig). }\end{array}$ \\
\hline $\begin{array}{l}\text { Kerja sama dengan } \\
\text { supplier atau } \\
\text { pemasok. }\end{array}$ & $\begin{array}{l}\text { Naiknya harga bahan } \\
\text { dan alat pembuatan } \\
\text { wig. }\end{array}$ \\
\hline $\begin{array}{l}\text { Mendapatkan } \\
\text { pelanggan tetap. }\end{array}$ & $\begin{array}{l}\text { Perkembangan } \\
\text { teknologi yang } \\
\text { semakin canggih. }\end{array}$ \\
\hline $\begin{array}{l}\text { Alat yang } \\
\text { digunakan } \\
\text { semakin canggih. }\end{array}$ & $\begin{array}{l}\text { Ketatnya persaingan } \\
\text { dalam hal promosi. }\end{array}$ \\
\hline
\end{tabular}

Untuk membuat perencanaan strategis yang baik dan sesuai dengan kebutuhan perusahaan, maka harus membuat strategi berdasarkan kekuatan, kelemahan, peluang, dan ancaman dari 
PT Mono Jaya. Berikut analisis strategi

SWOT PT Mono Jaya :

\section{Strategi SO (Strength - Opportunities)}

Tabel.3 Strategi kekuatan peluang

\begin{tabular}{|c|l|}
\hline No & \multicolumn{1}{|c|}{ Strategi S - O } \\
\hline 1 & $\begin{array}{l}\text { Memanfaatkan hubungan baik } \\
\text { antara perusahaan dengan mitra kerja. }\end{array}$ \\
\hline 2 & $\begin{array}{l}\text { Memanfaatkan citra perusahaan yang } \\
\text { baik }\end{array}$ \\
\hline 3 & $\begin{array}{l}\text { Memanfaatkan pengalaman } \\
\text { perusahaan dan memanfaatkan surat } \\
\text { ijin usaha untuk terus } \\
\text { mengembangkan perusahaan }\end{array}$ \\
\hline 4 & $\begin{array}{l}\text { Memanfaatkan SDM yang kompeten } \\
\text { dibidangnya untuk mempertahankan } \\
\text { perusahaan }\end{array}$ \\
\hline 5 & $\begin{array}{l}\text { Letak PT Mono Jaya strategis di } \\
\text { daerah Kroya }\end{array}$ \\
\hline 6 & $\begin{array}{l}\text { Memanfaatkan hubungan baik dengan } \\
\text { supplier untuk mendapatkan pemasok } \\
\text { tetap an bahan }\end{array}$ \\
\hline 7 & $\begin{array}{l}\text { Menggunakan alat dan } \\
\text { pembuatan wig yang berkualitas dan } \\
\text { sesuai dengan standar yang berlaku }\end{array}$ \\
\hline
\end{tabular}

\section{Strategi W-O (Weakness-Opportunities)}

Tabel 4. Kelemahan - peluang

\begin{tabular}{|c|l|}
\hline No & \multicolumn{3}{|c|}{ Strategi W - O } \\
\hline 1 & $\begin{array}{l}\text { Pendapatan keuntungan tergantung } \\
\text { dengan banyaknya pesanan rambut } \\
\text { palsu (wig) untuk mengatasi } \\
\text { permasalahan tersebut PT Mono Jaya } \\
\text { memiliki kerja sama dengan beberapa } \\
\text { perusahaan seperti PT Dalim Videta } \\
\text { Kornesia. }\end{array}$ \\
\hline 2 & $\begin{array}{l}\text { Membuat laporan keuangan secara } \\
\text { rutin untuk meminimalisir kesalahan } \\
\text { yang mungkin terjadi ketika } \\
\text { pembuatan laporan keuangan }\end{array}$ \\
\hline 3 & $\begin{array}{l}\text { Memanfaatkan peluang yang ada } \\
\text { untuk mempertahankan atau } \\
\text { mengembangkan bisnis PT Mono Jaya }\end{array}$ \\
\hline
\end{tabular}

Strategi S-T (Strenght - Threats)

Tabel 5. Kekuatan - ancaman

\begin{tabular}{|c|c|}
\hline No & Strategi $\mathrm{S}-\mathrm{T}$ \\
\hline 1 & $\begin{array}{l}\text { Memanfaatkan kerja sama dan } \\
\text { memanfaatkan hubungan baik dengan } \\
\text { mitra kerja dan supplier. }\end{array}$ \\
\hline 2 & $\begin{array}{l}\text { Mempekerjakan karyawan } \\
\text { berdasarkan kemampuan dan } \\
\text { pengalaman yang dimiliki, sehingga } \\
\text { PT Mono Jaya memiliki SDM yang } \\
\text { kompeten dibidangnya }\end{array}$ \\
\hline 3 & $\begin{array}{l}\text { Mempunyai kemampuan diskusi dan } \\
\text { komunikasi yang baik untuk } \\
\text { mengatasi kondisi lingkungan yang } \\
\text { tidak kondusif }\end{array}$ \\
\hline 4 & $\begin{array}{l}\text { Menjaga hubungan baik dengan mitra } \\
\text { kerja dan pelanggan dan memberikan } \\
\text { pelayanan yang maksimal }\end{array}$ \\
\hline
\end{tabular}

Strategi W-T (Weakness - Threats)

Tabel 6. Kelemahan - ancaman

\begin{tabular}{|c|l|}
\hline No & \multicolumn{3}{|c|}{ Strategi S-T } \\
\hline 1 & Memaksimalkan proses bisnis, \\
& sehingga PT Mono Jaya tidak akan \\
& kalah saing dengan perusahaan lain \\
& yang sejenis. \\
\hline 2 & Melakukan promosi yang gencar, \\
& sehingga banyak yang akan \\
& mengetahui produk rambut palsu \\
& (wig) yang berkualitas dari PT Mono \\
& Jaya \\
\hline 3 & Selalu melakukan evaluasi \\
\hline
\end{tabular}

Analisis Value Chain

Analisis Value Chain digunakan untuk memetakan seluruh proses kerja yang terjadi pada PT Mono Jaya yang terdiri dari dua kategori aktivitas yaitu, aktivitas utama dan aktivitas pendukung. Adapun hasil analisis Value Chain pada PT Mono Jaya dapat dilihat pada tabel 7: 
Tabel 7. Value chain

\begin{tabular}{|c|c|}
\hline No & Aktifitas Pendukung \\
\hline 1 & $\begin{array}{l}\text { Human Resources Management : } \\
\text { Perekrutan, pelatihan dan penggajian. }\end{array}$ \\
\hline 2 & $\begin{array}{l}\text { Technology Development : } \\
\text { Pemanfaatan dan pengembangan } \\
\text { sarana dan prasarana TI/SI }\end{array}$ \\
\hline 3 & $\begin{array}{l}\text { Procurement: } \\
\text { Rekruitment SDM, kerja sama dengan } \\
\text { mitra kerja, pengajuan pembelian } \\
\text { komputer. }\end{array}$ \\
\hline & Aktifitas Utama \\
\hline 1 & $\begin{array}{l}\text { Inbound Logistic: } \\
\text { a. Informasi stok barang. } \\
\text { b. Pengadaan tenaga kerja } \\
\text { (karyawan). } \\
\text { c. Persediaan bahan pembuat } \\
\text { rambut palsu (wig). }\end{array}$ \\
\hline 2 & $\begin{array}{l}\text { Operation : } \\
\text { a. Melakukan proses produksi. } \\
\text { b. Monitoring } \\
\text { gudang. } \\
\text { c. Laporan keuangan rutin } \\
\\
\quad \text { (harian, mingguan, bulanan } \\
\\
\text { dan akhir tahun). }\end{array}$ \\
\hline 3 & $\begin{aligned} \text { Outbound Logistic : } & \\
\text { a. } & \text { Laporan } \\
& \text { perusahaan. } \\
\text { b. } & \text { Melakukan } \\
& \text { barang. } \\
\text { c. } & \text { Kepuasan pelanggan. }\end{aligned}$ \\
\hline 4 & $\begin{array}{l}\text { Services : } \\
\text { a. Menjalin komunikasi } \\
\text { yang baik dengan konsumen } \\
\text { dan mitra kerja. } \\
\text { b. Menjalin hubungan yang baik } \\
\text { dengan pemasok. } \\
\text { c. Jaminan barang dalam } \\
\text { kondisi baik. }\end{array}$ \\
\hline
\end{tabular}

Identifikasi Critical Success Factor sebagai berikut :
Tabel 8. Critical success factor

\begin{tabular}{|c|c|c|}
\hline Tujuan Utama & $\begin{array}{l}\text { Critical Success } \\
\text { Factor (Action) }\end{array}$ & $\begin{array}{l}\text { Measure } \\
\text { (ukuran) }\end{array}$ \\
\hline $\begin{array}{l}\text { a. Mewujudkan } \\
\text { visi dan misi } \\
\text { PT Mono } \\
\text { Jaya. } \\
\text { b. Mewujudkan } \\
\text { proses bisnis } \\
\text { berkualitas. } \\
\text { c. Requitment } \\
\text { karyawan } \\
\text { berkualitas. }\end{array}$ & $\begin{array}{l}\text { a. Melahirkan SDM } \\
\text { yang kompeten } \\
\text { dibidangnya } \\
\text { b. Pelatihan/training } \\
\text { terhadap karyawan } \\
\text { baru. } \\
\text { c. Menyusun strategi } \\
\text { untuk perkembanga } \\
\text { PT Mono Jaya. } \\
\text { d. Melakukan } \\
\text { koordinasi dan } \\
\text { kontroling pada } \\
\text { administrasi, } \\
\text { keuangan, } \\
\text { peralatan, } \\
\text { perlengkapan dan } \\
\text { kepegawaian. } \\
\text { e. Melakukan } \\
\text { kontroling terhadap } \\
\text { kinerja pegawai }\end{array}$ & 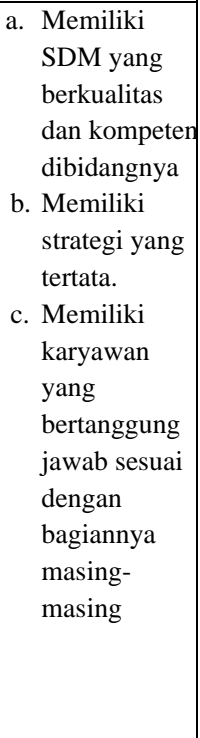 \\
\hline $\begin{array}{l}\text { Mengatur } \\
\text { keuangan agar } \\
\text { dapat dikelola } \\
\text { dengan baik }\end{array}$ & $\begin{array}{l}\text { Menjaga kepercayaan } \\
\text { pimpinan dengan } \\
\text { laporan yang baik }\end{array}$ & $\begin{array}{l}\text { Perusahaan } \\
\text { puas dengan } \\
\text { laporan } \\
\text { keuangan yang } \\
\text { telah dibuat }\end{array}$ \\
\hline $\begin{array}{l}\text { Pemilihan bahan } \\
\text { pembuatan wig } \\
\text { yang berkualitas } \\
\text { dan aman sesuai } \\
\text { dengan standar } \\
\text { yang berlaku }\end{array}$ & $\begin{array}{l}\text { Mengkoordinasi } \\
\text { proses pembuatan } \\
\text { rambut palsu (wig) } \\
\text { apakah produksi } \\
\text { berjalan sesuai } \\
\text { dengan standar yang } \\
\text { berlaku atau tidak. }\end{array}$ & $\begin{array}{l}\text { Profit } \\
\text { penjualan } \\
\text { meningkat, } \\
\text { mendapatkan } \\
\text { pelanggan } \\
\text { tetap, } \\
\text { perusahaan } \\
\text { menjadi lebih } \\
\text { maju dan } \\
\text { perusahaan } \\
\text { menjadi lebih } \\
\text { berkembang. }\end{array}$ \\
\hline $\begin{array}{l}\text { Pengawasan } \\
\text { terhadap gudang }\end{array}$ & $\begin{array}{l}\text { Mengetahui dan } \\
\text { memonitoring } \\
\text { persediaan stok } \\
\text { barang jadi dan } \\
\text { barang belum jadi } \\
\text { (bahan pembuatan } \\
\text { wig) yang ada di } \\
\text { gudang }\end{array}$ & $\begin{array}{l}\text { Tidak pernah } \\
\text { kekurangan } \\
\text { bahan untuk } \\
\text { pembuatan } \\
\text { wig, karena } \\
\text { persediaan } \\
\text { barang di } \\
\text { gudang } \\
\text { menjadi lebih } \\
\text { terkontrol }\end{array}$ \\
\hline $\begin{array}{l}\text { Membangun } \\
\text { hubungan yang } \\
\text { baik dengan } \\
\text { konsumen }\end{array}$ & $\begin{array}{l}\text { Meningkatkan proses } \\
\text { pemasaran dengan } \\
\text { menggunakan media } \\
\text { sosial ataupun } \\
\text { website }\end{array}$ & $\begin{array}{l}\text { a. Memiliki } \\
\text { konsumen } \\
\text { tetap } \\
\text { b. Profit } \\
\text { penjualan } \\
\text { semakin } \\
\text { meningkat } \\
\text { c. Produk wig } \\
\text { menjadi } \\
\text { semakin } \\
\text { dikenal oleh } \\
\text { konsumen. }\end{array}$ \\
\hline
\end{tabular}




\section{Analisis Balanced Scorecard}

Analisis lingkungan bisnis PT Mono Jaya dengan analisis Balanced Scorecard dapat dilihat pada tabel berikut:

Tabel 9. Balanced scorecard

\begin{tabular}{|c|c|}
\hline Strategi & Measure \\
\hline $\begin{array}{l}\text { a. Mengontrol } \\
\text { laporan } \\
\text { keuangan } \\
\text { b. Meningkatan } \\
\text { pendapatan dan } \\
\text { mampu } \\
\text { mempertahank } \\
\text { an pendapatan } \\
\text { perusahaan } \\
\text { c. Pembiayaan } \\
\text { operasional } \\
\text { yang dapat } \\
\text { bermanfaat bagi } \\
\text { perusahaan }\end{array}$ & $\begin{array}{l}\text { a. Memantau } \\
\text { perkembangan } \\
\text { PT Mono Jaya. } \\
\text { b. Profit stabil dan } \\
\text { bahkan } \\
\text { mengalami } \\
\text { kemajuan setiap } \\
\text { tahunnya } \\
\text { c. Melakukan } \\
\text { kegiatan yang } \\
\text { bermanfaat } \\
\text { untuk } \\
\text { perusahaan } \\
\text { d. Memelihara } \\
\text { sarana dan } \\
\text { prasarana PT } \\
\text { Mono Jaya } \\
\text { Melakukan } \\
\text { pengecekan } \\
\text { pengadaan } \\
\text { barang }\end{array}$ \\
\hline $\begin{array}{l}\text { a. Mempertahankan } \\
\text { kualitas terbaik } \\
\text { produk yang } \\
\text { dihasilkan PT } \\
\text { Mono Jaya } \\
\text { b. Menjaga } \\
\text { hubungan baik } \\
\text { dengan mitra } \\
\text { kerja seperti PT } \\
\text { Dalim Videta } \\
\text { Kornesia agar } \\
\text { mau tetap bekerja } \\
\text { sama dengan PT } \\
\text { Mono Jaya }\end{array}$ & $\begin{array}{l}\text { a. Memantau } \\
\text { perkembangan } \\
\text { pelayanan } \\
\text { karyawan PT } \\
\text { Mono Jaya } \\
\text { kepada } \\
\text { konsumen. } \\
\text { b. Memantau } \\
\text { kualitas produk } \\
\text { PT Mono Jaya } \\
\text { c. Hasil produksi } \\
\text { berkualitas, } \\
\text { nyaman saat } \\
\text { digunakan }\end{array}$ \\
\hline
\end{tabular}

\begin{tabular}{|l|l|}
\hline $\begin{array}{l}\text { c. Mempertahan } \\
\text { kan konsumen } \\
\text { agar memiliki } \\
\text { pelanggan tetap }\end{array}$ & $\begin{array}{l}\text { d. Hubungan dengan } \\
\text { mitra kerja sangat } \\
\text { baik }\end{array}$ \\
& $\begin{array}{l}\text { e. Konsumen } \\
\text { mempercayakan } \\
\text { kualitas produk } \\
\end{array}$ \\
& yang baik \\
\hline
\end{tabular}

Analisis Bisnis Eksternal

Analisis Five Force Model Porter

Analisis bisnis PT Mono Jaya dengan analisis Five Force Model Porter dapat dilihat pada tabel berikut:

Tabel 10. Five force model porter

\begin{tabular}{|c|c|}
\hline No & Analisis Five force model porter \\
\hline 1 & $\begin{array}{l}\text { Perusahaan yang sudah ada : } \\
\text { - } \quad \text { PT Bio Takara } \\
\text { - } \quad \text { PT Boyang Industrial } \\
\text { - } \quad \text { PT Mahkota Etetika Abadi }\end{array}$ \\
\hline 2 & $\begin{array}{ll} & \text { Pendatang Baru: } \\
\text { - } & \text { PT Shun Chang } \\
\text { - } & \text { PT Kokoria }\end{array}$ \\
\hline 3 & $\begin{array}{l}\text { Supplier : } \\
\text { Hair Suniraja }\end{array}$ \\
\hline 4 & $\begin{array}{ll} & \text { Konsumen : } \\
\text { - } & \text { Rinna Salon } \\
\text { - } & \text { Widya Salon } \\
\text { - } & \text { Fashion Hair Extension } \\
\text { - } & \text { Tamini Squere }\end{array}$ \\
\hline 5 & $\begin{array}{ll} & \text { Produk Pengganti : } \\
\text { - } & \text { Rambut Kuda, Rambut manusia } \\
\text { - } & \text { Rambut Kerbau }\end{array}$ \\
\hline
\end{tabular}

Rancangan Portofolio Aplikasi Yang Akan Datang.

Selanjutnya solusi-solusi sistem informasi tersebut akan dipetakan dalam portofolio McFarlan Strategic Grid. Portofolio sistem informasi yang dihasilkan pada tahap ini adalah 
portofolio sistem informasi yang dibutuhkan oleh PT Mono Jaya.

a. High Potential

Aplikasi yang mungkin penting dalam mencapai keunggulan kompetitif perusahaan. Usulan sistem informasinya yaitu Website PT Mono Jaya. Diharapkan website tersebut dapat mendukung proses bisnis PT Mono Jaya dimasa sekarang dan dimasa yang akan datang, sehingga PT Mono Jaya dapat berkembang lebih pesat lagi.

b. Key Operation

Sistem informasi yang penting untuk mendukung kelangsungan bisnis PT Mono Jaya dan harus selalu dijaga keefektifannya agar berjalan dengan baik. Adapun usulan sistem informasi nya yaitu $C C T V$, SI Keuangan PT Mono Jaya dan SI Kepegawaian. Ketiga usulan tersebut nantinya akan berpengaruh terhadap kemajuan PT Mono Jaya.

c. Strategic

Sistem informasi yang memiliki pengaruh besar untuk kesuksesan PT Mono Jaya, yang masuk dalam kategori sistem informasi ini yaitu Knowledge Management
System danmedia sosial PT Mono Jaya. Sistem informasi ini memiliki pengaruh besar untuk kesuksesan PT Mono Jaya dimasa yang akan datang, karena dengan adanya media sosial maka akan lebih banyak lagi orang-orang atau masyarakat yang mengenal atau mengetahui produk rambut palsu (wig) yang diproduksi oleh PT Mono Jaya

d. Support

Dalam hal ini support merupakan aplikasi yang bernilai tetapi tidak kritis dalam mencapai kesuksesan suatu perusahaan atau sistem informasi pendukung saja, yang masuk kategori sistem informasi ini yaitu SI Persediaan Gudang, SI Supplier dan SI Penerimaan Tamu. Dengan adanya SI Persediaan Gudang maka semua barang yang ada di gudang menjadi lebih terkontrol, baik dalam hal jumlah barang mentah (bahan pembuatan rambut palsu) ataupun jumlah barang jadi (rambut palsu/wig). Sedangkan SI Supplier dapat membantu perusahaan dalam melancarkan proses bisnisnya, salah satunya dapat menyimpan 
semua data pembelian bahan pembuatan wig.

\section{SIMPULAN}

1. Penelitian ini menghasilkan portofolio sistem informasi yang sesuai dengan kebutuhan PT Mono Jaya guna meningkatkan daya saing perusahaan.

2. Sistem informasi yang dihasilkan yaitu : Knowledge Management System, Media Sosial PT Mono Jaya, Website PT Mono Jaya, CCTV, SI Keuangan PT Mono Jaya, SI Kepegawaian, SI Persediaan Gudang, SI Supplier dan SI Penerimaan Tamu. Sistem informasi tersebut berguna untuk meningkatkan daya saing perusahaan.

\section{SARAN}

1. Diharapkan dalam penelitian selanjutnya dapat menggunakan tools lain yang dapat mendukung perencanaan strategis SI/TI sesuai dengan kebutuhan Perusahaan.

2. Diharapkan penelitian yang selanjutnya menganalisis untuk perencanaan teknologi informasi dan jaringan.

3. Diharapkan PT Mono Jaya menerapkan sistem informasi manajemen guna meningkatkan daya saing perusahaan.

\section{DAFTAR PUSTAKA}

Anharudin. (2015). Perencanaan Strategis Sistem Informasi Untuk Meningkatkan Pelayanan Menggunakan Metode Ward And Peppard ( Studi Kasus: Pt Pos Indonesia Cilegon - Banten). Jurnal PROSISKO, 2(2), 1-4. Retrieved from http://ejurnal.lppmunsera.org/index.php/PR OSISKO/article/view/103/161

Arikunto. (2010). Prosedur penelitian: Suatu Pendekatan Praktik. (Edisi Revisi). Jakarta: Rineka Cipta.

Brumec, J., \& Vř , N. (2002). Strategic Planning of Information Systems ( SPIS ) - A Survey of. Journal of Computing and Information Technology, 225-231.

Fahana, J. (2018). Perencanaan Strategis Sistem Informasi untuk Pengelolaan Guru Sekolah Muhammadiyah. 4(1).

Hoque, M. R., Hossin, M. E., \& Khan, W. (2016). Strategic Information Systems Planning (SISP) Practices In Health Care Sectors Of Bangladesh. European Scientific Journal, ESJ, 12(6), 307. https://doi.org/10.19044/esj.2016.v1 2n6p307

Kantor Kependudukan dan Catatan Sipil Kab. Cilacap. (2008). Kondisi Geografis Daerah. Retrieved from http://cilacapkab.go.id/v2/index.php ?pilih=hal\&id=3

Khani, N., Nor, K., Bahrami, M., \& 
Hakimpoor, H. (2012). Antecedents , Drivers, and Success of Strategic Information Systems Planning: A Resource-Based View. 40, 334-340. https://doi.org/10.1016/j.sbspro.201 2.03.196

Mawlan, S. (n.d.). Perencanaan Strategis Sistem Informasi / Teknologi Informasi Pada Perusahaan Penjualan Mobil Dengan Pendekatan Jhon Ward And Joe Peppard Studi Kasus : PT Topcars Cabang Palembang. 1-8.

Saravi, M. M. (2016). The Effect of Strategic Planning of Information Systems in Improving the Performance of a Supply Chain. 1646-1660.

Sekaran, uma dan R. B. (2010). Edisi 5, Research Method For Business: A Skill Building Approach. New York: John Wiley Sons.

Septiana, Y. (2017). Perencanaan Strategis Sistem Informasi Dengan Pendekatan Ward And Peppard Model ( Studi Kasus : Klinik INTI Garut ) PERENCANAAN STRATEGIS SISTEM INFORMASI DENGAN PENDEKATAN WARD AND PEPPARD MODEL ( Studi Kasus : Klinik INTI Garut ). Wawasan Ilmiah, 8(May), 8-24.

Sudaryono. (2015). Metodologi Riset di Bidang TI. Yogyakarta: CV Andi Offset.

Sugiyanto. (2012). Metode Penelitian Kuantitatif Kualitatif dan $R \& D$. Bandung: Alfabeta.

Sunyoto, D. (2013). Metodologi Penelitian Akuntansi. Bandung: PT Refika Aditama.
Sunyoto, D. (2016). Metodologi Penelitian Akuntansi. Bandung: PT Refika Aditama.

Ward, J., \& Peppard, J. O. E. (n.d.). AM Strategic Planning for Information Systems.

Wijaya, A., \& Widiawan, K. (2017). Perancangan Business Continuity Plan Sebuah Perusahaan Paku di Surabaya. 5(2), 123-130. 